\title{
Sensitivity of Monilinia fructicola from Stone Fruit to Thiophanate-Methyl, Iprodione, and Tebuconazole
}

\author{
Michael A. Yoshimura, Biological Sciences Department, California Polytechnic State University, San Luis Obispo \\ 93407; and Yong Luo, Zhonghua Ma, and Themis J. Michailides, Department of Plant Pathology, University of \\ California-Davis, Kearney Agricultural Center, Parlier 93648
}

\begin{abstract}
Yoshimura, M. A., Luo, Y., Ma, Z., and Michailides, T. J. 2004. Sensitivity of Monilinia fructicola from stone fruit to thiophanate-methyl, iprodione, and tebuconazole. Plant Dis. 88:373-378.

Sensitivity in Monilinia fructicola to three fungicides was determined by measuring mycelial growth in fungicide-amended media. Resistance to thiophanate-methyl was found in 39 of 52 isolates (75\%) collected from 1992 to 1998 (historic population) and 22 of 100 isolates (22\%) collected in 2002 (current population). Three groups having distinct ranges of values for 50\% effective concentration $\left(\mathrm{EC}_{50}\right)$ to thiophanate-methyl were identified. Benzimidazole-sensitive (benS) isolates had $\mathrm{EC}_{50}$ values less than 2.0, low-resistant (benL) isolates between 2.0 and 30.0 , and high-resistant (benH) isolates greater than $30.0 \mu \mathrm{g} / \mathrm{ml}$. One (2\%) isolate from the historic and three $(3 \%)$ isolates from the current population were benH. Inoculation of untreated nectarine blossoms with four isolates from each of the three groups, individually or combined using equal numbers of conidia from each isolate, showed that the benS, benL, and benH isolates were equally pathogenic and competitive. Use of thiophanate-methyl at $300 \mu \mathrm{g}$ a.i./ml (half dosage) and $600 \mu \mathrm{g}$ a.i./ml (full dosage) effectively reduced the percentage of blighted blossoms caused by the benS group but not that caused by the benL and benH groups. The benH isolates caused significantly greater percentage of blighted blossoms than the benL isolates at both dosage levels. None of the tested isolates of $M$. fructicola were resistant to either iprodione or tebuconazole.
\end{abstract}

Additional keywords: blossom blight, brown rot, fungicide resistance

Approximately 121,000 of the 162,000 ha of stone fruit, including apricot, cherry, nectarine, peach, plum, and prune, grown in the United States are grown in California. Brown rot, caused by Monilinia fructicola (G. Wint.) Honey $(3,8,10,11)$ is the most destructive fungal disease, causing significant losses in stone fruit production. The pathogen causes blossom blight in the spring and fruit rot of mature fruit late in the season. Use of fungicides is a major tactic to control this disease. Fungicides generally are applied once or twice per year in plum and prune orchards and three to four times in peach and nectarine orchards. Frequent use of fungicides can lead to the development of resistance by fungi and the loss of efficacy of specific chemicals (2).

Resistance of $M$. fructicola to the benzimidazole fungicide benomyl was first

Corresponding authors: T. J. Michailides

E-mail themis@uckac.edu

and Y. Luo

E-mail: yluo@uckac.edu

This study was part of a research project funded by USDA/CAR Aw. No. 2002-5/100-01990.

Accepted for publication 2 December 2003.

Publication no. D-2004-0127-01R

(C) 2004 The American Phytopathological Society reported in California in 1977, 5 years after the fungicide was introduced for control of brown rot (22). Resistant isolates have been found throughout the state $(1,12,19)$. Levels of resistance to benomyl have been relatively low in California, with values for $50 \%$ effective concentration $\left(\mathrm{EC}_{50}\right)$ between 0.5 and $4 \mu \mathrm{g} / \mathrm{ml}(12,14)$, when compared with $\mathrm{EC}_{50}$ values of 50 $\mu \mathrm{g} / \mathrm{ml}$ or higher reported from other states $(9,22,28)$ and Australia (23). Although benomyl was withdrawn from the market, growers still can use thiophanate-methyl, another benzimidazole, as a replacement for benomyl.

Iprodione has been used in the United States on stone fruit for control of brown rot for close to two decades, but resistance to iprodione in $M$. fructicola has not yet been reported in field isolates in the United States. However, resistance to iprodione has been found only in stone fruit orchards in New Zealand (6), and resistant mutants have been produced in the laboratory (15). Reduced sensitivity to iprodione also has been reported in M. fructicola isolates in Australia (24).

The demethylation-inhibiting (DMI) fungicides such as tebuconazole also have been used widely in the last several years. No resistance in $M$. fructicola to this group has been found, although reduced sensitivities to propiconazole have been reported $(24,27)$. It is important to determine possible changes in the sensitivity of $M$. fructicola isolates to these fungicides over time.

The objectives of this study were to (i) survey $M$. fructicola isolates for frequencies and levels of sensitivity to thiophanatemethyl and tebuconazole, (ii) compare the pathogenicity and competitiveness among the benzimidazole-sensitive (benS), lowresistant (benL), and high-resistant (benH) isolates of M. fructicola, and (iii) determine the effects of thiophanate-methyl on the benS, benL, and benH isolates.

\section{MATERIALS AND METHODS}

Isolates. In the fall of 2002, isolates of M. fructicola were collected from rotting and mummified fruit on the floor of 15 peach, nectarine, and plum orchards in Fresno, Madera, and Merced Counties, CA. Isolates of M. fructicola also were obtained in 2002 from mummified fruit collected from drying plants before fruit dehydration in Yuba, Butte, and Sutter Counties, CA. Isolates in the culture collection of the Department of Plant Pathology at the University of California Kearney Agricultural Center, collected from peach, nectarine, and plum orchards in California between 1992 and 1998, also were used. In all, 25 isolates from each of peach, nectarine, plum, and prune collected in 2002, 25 isolates collected in 1998, and 27 isolates collected from 1992 to 1995 were used in this study. Singlespore isolates from all collections were obtained by streaking conidia onto acidified $(2.5 \mathrm{ml}$ of $25 \%$ [vol/vol] lactic acid per liter) potato dextrose agar (APDA; Microtech Scientific, Orange, CA) in petri dishes at 23 to $25^{\circ} \mathrm{C}$ and, 1 day later, transferring individual germinating conidia to fresh APDA.

Survey of fungicide sensitivity. Thiophanate methyl (Topsin M 70 WP; Elf Atochem North America, Inc., Philadelphia) was suspended in sterile water, adjusted to a concentration of $10 \mathrm{mg}$ a.i. $/ \mathrm{ml}$, and added to potato dextrose agar (PDA) medium after sterilization to produce final concentrations of $0,0.25,0.5,1.0,2.0,4.0$, and $8.0 \mu \mathrm{g}$ a.i./ml of medium. Additional concentrations of 16,32 , and $100 \mu \mathrm{g}$ a.i./ml also were used. Technical iprodione (a.i. 95\%; Rhone-Poulenc Ag Company, Research Triangle Park, NC) was dissolved in acetone at $10 \mathrm{mg}$ a.i./ml and added to PDA after sterilization to produce 
final concentrations of $0,0.06,0.18,0.54$, 1.62 , and $4.86 \mu \mathrm{g}$ a.i./ml of medium. Technical tebuconazole (a.i. 97.5\%; Bayer Corporation, Kansas City, MO) was dissolved in $100 \%$ ethanol, adjusted to a concentration of $10 \mathrm{mg}$ a.i./ml, and added to PDA after sterilization to produce final concentrations of $0,0.005,0.015,0.045,0.135$, and $0.405 \mu \mathrm{g}$ a.i. $/ \mathrm{ml}$ of medium.

A 5-mm mycelial plug was cut from the edge of a 4-day-old colony on APDA for each isolate of $M$. fructicola tested and placed in the center of PDA dishes, each amended with one of the fungicide concentrations. Two plates for each concentration of each fungicide were used. The cultures were incubated at $25^{\circ} \mathrm{C}$ for 3 days. The mean diameter of each colony was measured in two perpendicular directions, and the diameter of the original mycelial plug $(5 \mathrm{~mm})$ was subtracted.

For each concentration of each fungicide, the inhibition of colony growth $\left(I_{i}\right)$ of isolate $i$ was calculated by $I_{i}=\left(C_{\mathrm{ck}}-\right.$ $\left.C_{i}\right) / C_{\mathrm{ck}} \times 100$, where, $C_{\mathrm{ck}}$ was the mean colony diameter for the control with no fungicide amended, and $C_{\mathrm{i}}$ was the mean colony diameter for isolate $i$. The concentrations of fungicides were logarithm $\left(\log _{10}\right)$ transformed. Linear regressions of the $I$ values on $\log$ concentration were performed with the REG procedure of SAS (version 8.0; SAS Institute, Cary, NC). The $\mathrm{EC}_{50}$ value for each fungicide was calculated from the corresponding regression equation for this isolate when the regression was significant at $\alpha=0.05$. The initial linear regressions of 13 isolates were not significant. These isolates were further tested on media amended with thiophanate-methyl at 2, 4, 8, 16, 32, and $100 \mu \mathrm{g}$ a.i. ml.

The whole range of $\mathrm{EC}_{50}$ values was divided into several groups with an equal interval. The arithmetic mean $\mathrm{EC}_{50}$ was calculated for each group, and the frequency of isolates for each group also was determined. These frequency data for the historic (1992-98) population and the current (2002) population were used to produce the distributions of $\mathrm{EC}_{50}$ values. For each fungicide, comparisons were conducted with the NPAR1WAY procedure of SAS by using the Kuiper test to determine significant differences in distribution of $\mathrm{EC}_{50}$ values between the two populations.

After a determination of significance in distributions of $\mathrm{EC}_{50}$ values between the two populations, a nonlinear regression using the distribution data was conducted with SigmaPlot (version 5.0; SPSS Inc., Richmond, CA). A lognormal function was used to describe the distribution of percentage (PROP) of $\mathrm{EC}_{50}$ isolates for each population: $\mathrm{PROP}=P \times \exp \{-0.5$ $\left.[\ln (E / \alpha) / \beta]^{2}\right\}$, where $P$ is a parameter that determines the maximum PROP at the peak of distribution curve, $E$ is $\mathrm{EC}_{50}$, and $\alpha$ and $\beta$ are parameters of the function.
Pathogenicity test for benzimidazoleresistance groups and efficacy of thiophanate-methyl. The pathogenicity of the three benzimidazole sensitivity groups, benS, benL and benH, was tested. For each group, four isolates, one from peach, one from plum, and two from nectarine were selected based on a classification of $M$. fructicola isolates for fungicide resistance from a molecular study (Z. Ma, unpublished data). These 12 isolates were grown on $10 \%$ vegetable juice agar (100 $\mathrm{ml}$ of V8 Juice, $2 \mathrm{~g}$ of $\mathrm{CaCO}_{3}, 15 \mathrm{~g}$ of agar per liter) at 23 to $25^{\circ} \mathrm{C}$ for 7 days.

In spring 2003, nectarine (Prunus persica var. nectarina cv. Fantasia) shoots, each bearing six to eight blossoms at the popcorn (unopened flower) to the early full-bloom stages, were collected from an orchard at the Kearney Agricultural Center in Parlier, CA. Shoots were dipped for $20 \mathrm{~s}$ in a suspension of thiophanate-methyl (Topsin M $70 \mathrm{WP}$ ) at $600 \mu \mathrm{g}$ a.i./ml, the recommended rate of application, or 300 $\mu \mathrm{g}$ a.i./ml, half the recommended rate. The shoots were air dried for $1 \mathrm{~h}$, then placed in plastic bags at room temperature overnight. The following morning, the shoots were placed on plastic racks in covered plastic containers (32 by 23.5 by $11 \mathrm{~cm}$ ). To maintain freshness of the shoots and blossoms, the cut ends of the branches were covered with wet paper towels that were in contact with water under the rack. Each plastic container contained seven or eight shoots with a total of 50 to 60 blossoms. Nonfungicide-treated shoots were used as controls. Two plastic containers were used for each isolate and each fungicide concentration and untreated control.

To obtain a spore suspension, $3 \mathrm{ml}$ of sterile distilled water were poured in each culture, and a glass rod was used to harvest spores of $M$. fructicola. For each isolate, $200 \mathrm{ml}$ of a suspension containing 5,000 conidia/ml in $0.05 \%$ Tween 20 was prepared for inoculation. Using a hand-held sprayer, approximately $20 \mathrm{ml}$ of the conidial suspension for each isolate was applied to the blossoms in each plastic container. The plastic containers were covered for approximately $40 \mathrm{~h}$, partially uncovered for $24 \mathrm{~h}$, the blossoms lightly sprayed with sterile water, and the containers covered again for 3 days. The experiments were performed in a laboratory at 22 to $26^{\circ} \mathrm{C}$. Six days after inoculation, the total number of blossoms and blighted blossoms with visible sporulation of $M$. fructicola was recorded. The experiment was repeated once.

The percentage of blighted blossoms (PBB) for each of two plastic containers in each replicated experiment was subjected to analysis of variance (ANOVA). A splitplot design was used with experiment treated as replication, resistance group as the main plot factor, and fungicide dosage as the subplot factor. The GLM procedure of SAS was used and the corresponding error items were applied to determine the significant differences among experiments, sensitivity groups, and fungicide dosages. After determination of nonsignificant difference in PBB between the experiments, the data from the two experiments were combined. Pairwise comparisons in PBB between sensitivity groups for each fungicide dosage were conducted using Fisher's least significant difference.

Competition among benzimidazolesensitive, -low-resistant, and -highresistant isolates. Included with the pathogenicity test experiments, an additional spore suspension $(5,000$ conidia/ml) containing $15 \mathrm{ml}$ of each of the 12 isolates used in the pathogenicity test also was used to inoculate nectarine blossoms as described above. One week after inoculation, conidia from each blighted blossom with sporulation of $M$. fructicola were streaked onto APDA and incubated at 23 to $25^{\circ} \mathrm{C}$. One day later, a single germinated conidium was transferred to fresh APDA to obtain a single-spore isolate. Because previous experiments showed similar responses to both benomyl and thiophanate methyl, only benomyl was used in the following experiments. A 5-mm mycelial plug of each single-spore isolate was placed on PDA amended with benomyl at 1 or $500 \mu \mathrm{g}$ a.i./ml. Two replicate plates were used for each fungicide concentration. After 3 and 7 days of incubation at room temperature (23 to $25^{\circ} \mathrm{C}$ ), the isolates that did not grow at either fungicide concentration were recorded as benS isolates. Those that grew at 1 but not $500 \mu \mathrm{g} / \mathrm{ml}$ were recorded as benL isolates. Those that grew at both fungicide concentrations were recorded as benH isolates.

The numbers of isolates belonging to each sensitivity group were recorded. The percentage of isolates (PI) in each of these groups was calculated for each plastic container, and four plastic containers were used as four replicates for each fungicide concentration. Treatments were analyzed in a randomized complete block design, and the significance of variances in PI from fungicide treatments and from resistance groups was determined using the ANOVA procedure of SAS. After determination of significance of interaction between fungicide treatment and resistance group, pairwise comparisons of PI among the three resistance groups for each fungicide treatment were determined with $\chi^{2}$ values (7).

\section{RESULTS}

Sensitivity to thiophanate-methyl. There was no significant difference in the mean $\mathrm{EC}_{50}$ between the isolates collected from 1992 to 1995 and those collected in 1998; thus, these isolates were combined as the historic population. Both historic and current (2002) populations had $\mathrm{EC}_{50}$ values that ranged from 0.17 to greater 
than $30 \mu \mathrm{g} / \mathrm{ml}$ (Fig. 1). The mean $\mathrm{EC}_{50}$ for the historic population was $3.06 \mu \mathrm{g} / \mathrm{ml}$, whereas the mean $\mathrm{EC}_{50}$ for the current population was $1.19 \mu \mathrm{g} / \mathrm{ml}$. A $t$ test indicated that the mean $\mathrm{EC}_{50}$ of the current population was significantly lower $(P<$ $0.0001)$ than that of the historic population. The distributions of $\mathrm{EC}_{50}$ values between the two populations were significantly different at $P<0.001(\mathrm{Ka}=3.26)$. However, from regression analyses, none of the lognormal equations was significant to describe either of the distributions. Three distinct sensitivity groups were apparent. A benS group had $\mathrm{EC}_{50}$ values of less than $2 \mu \mathrm{g} / \mathrm{ml}$, a benL group had $\mathrm{EC}_{50}$ values between 2 and $30 \mu \mathrm{g} / \mathrm{ml}$, and a benH group had $\mathrm{EC}_{50}$ values greater than $30 \mu \mathrm{g} / \mathrm{ml}$.

Of 52 isolates of the historic population, $39(75 \%)$ had $\mathrm{EC}_{50}$ values greater than 2 $\mu \mathrm{g} / \mathrm{ml}$, whereas 22 of 100 isolates (22\%) of the current population had $\mathrm{EC}_{50}$ values greater than $2 \mu \mathrm{g} / \mathrm{ml}$. When the historic population was further separated, $85.2 \%$ of isolates collected from 1992 to 1995 and $64 \%$ of isolates collected in 1998 had $\mathrm{EC}_{50}$ values greater than $2 \mu \mathrm{g} / \mathrm{ml}$. Of the resistant isolates from the historic population, $38(73 \%)$ were benL and $1(2 \%)$ was benH. Of the resistant isolates from the current population, 19 (19\%) were benL and $3(3 \%)$ were benH. Resistant isolates were collected from 9 of the 16 orchards $(56 \%)$ sampled in 2002.

Sensitivity to iprodione. No significant difference in mean $\mathrm{EC}_{50}$ between the isolates collected from 1992 to 1995 and those collected in 1998 was found, and these isolates were combined as the historic population. For the historic population, the $\mathrm{EC}_{50}$ values for iprodione ranged from 0.01 to $0.36 \mu \mathrm{g} / \mathrm{ml}$ with a mean of $0.12 \mu \mathrm{g} / \mathrm{ml}$, and those of the current population ranged from 0.01 to $0.65 \mu \mathrm{g} / \mathrm{ml}$ with a mean of $0.21 \mu \mathrm{g} / \mathrm{ml}$ (Fig. 2A). Comparison of the distribution of $\mathrm{EC}_{50}$ values showed a significant difference between the two populations at $\mathrm{Ka}=3.50$ with $P<$ 0.0001 . Two lognormal equations were obtained from regression analyses to describe the distributions of $\mathrm{EC}_{50}$ values for the two populations (Fig. 2B). The parameter $P$ was 10.3 for the historic population and 7.0 for the current population. The parameter $\alpha$ was 0.08 for the historic population and 0.19 for the current population. The parameter $\beta$ was 0.51 for the historic population and 0.28 for the current population (Fig. 2B).

A correlation analysis of $\mathrm{EC}_{50}$ values between iprodione and thiophanate-methyl using the data from the same set of isolates showed no significance at $P>0.05$. Sensitivity to thiophanate-methyl was not correlated with sensitivity to iprodione, indicating the absence of dual resistance to these two fungicides.

Sensitivity to tebuconazole. For tebuconazole, the $\mathrm{EC}_{50}$ values for the historic population ranged from 0.001 to 0.053 $\mu \mathrm{g} / \mathrm{ml}$ with a mean $\mathrm{EC}_{50}$ of $0.0161 \mu \mathrm{g} / \mathrm{ml}$, and the $\mathrm{EC}_{50}$ values for the current population ranged from 0.0059 to $0.0607 \mu \mathrm{g} / \mathrm{ml}$ with a mean of $0.0175 \mu \mathrm{g} / \mathrm{ml}$ (Fig. 3A). However, statistical analysis demonstrated that the distributions of $\mathrm{EC}_{50}$ values be- tween the two populations were not significantly different $(\mathrm{Ka}=1.583723$ and $P$ $=0.1197)$. A $t$ test indicated no significant difference $(P=0.45)$ in the mean $\mathrm{EC}_{50}$ between these two populations. After combining the two data sets, a lognormal equation was obtained from a regression analy-

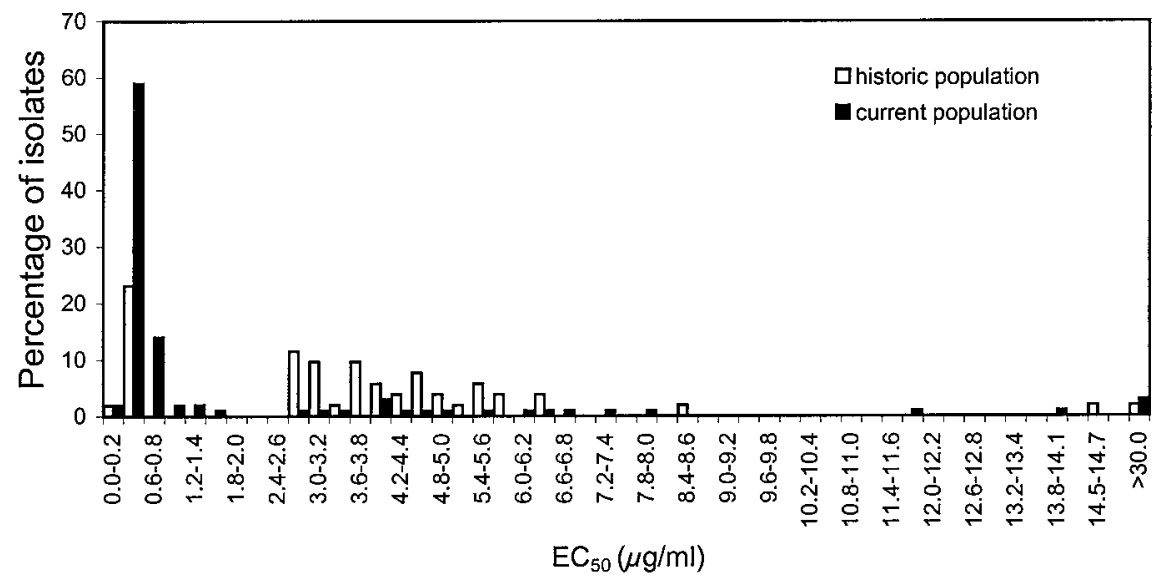

Fig. 1. Distribution of values for $50 \%$ effective concentration $\left(\mathrm{EC}_{50}\right)$ of thiophanate-methyl in historic and current populations of Monilinia fructicola from stone fruit in California. The historic population was collected during 1992 to 1998 and the current population in 2002. The Kuiper test (NPAR1WAY procedure of SAS) showed a significant difference in distribution of $\mathrm{EC}_{50}$ values between these populations.

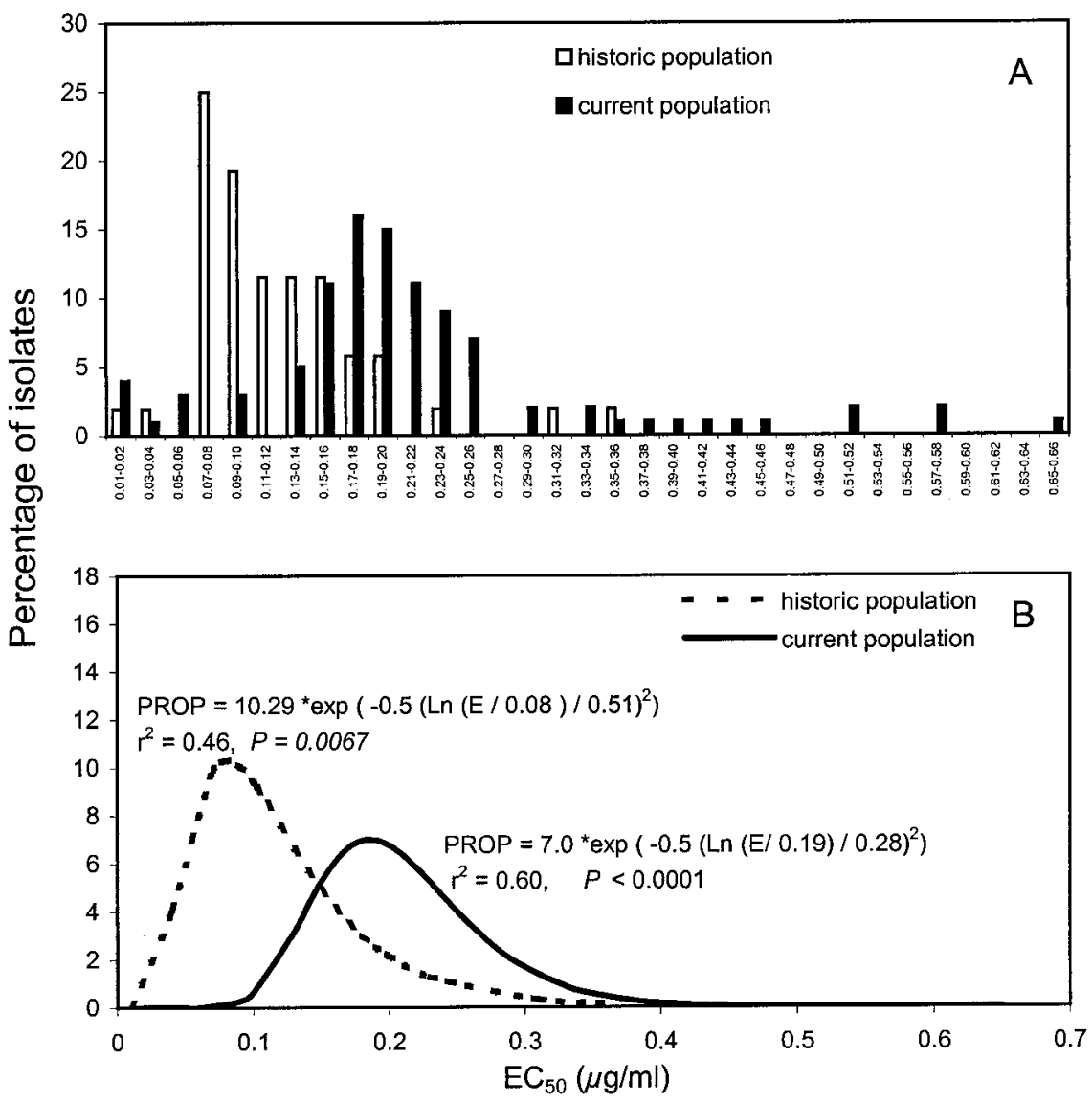

Fig. 2. Distribution of values for $50 \%$ effective concentration $\left(\mathrm{EC}_{50}\right)$ of iprodione in historic and current populations of Monilinia fructicola from stone fruit in California. A, The historic population was collected during 1992 to 1998 and the current population in 2002. The Kuiper test (NPAR1WAY procedure of SAS) showed a significant difference in distribution of $\mathrm{EC}_{50}$ values between these two populations. B, Lognormal regression described the distribution of each population. 
sis to describe the distribution of $\mathrm{EC}_{50}$ values for the $M$. fructicola populations to tebuconazole (Fig. 3B). Most of the $\mathrm{EC}_{50}$ values were between 0.005 and 0.025 $\mu \mathrm{g} / \mathrm{ml}$, and only $4 \%$ of the isolates had $\mathrm{EC}_{50}$ values greater than $0.025 \mu \mathrm{g} / \mathrm{ml}$.

Pathogenicity of benzimidazole sensitivity groups and efficacy of thiophanate-methyl. In the pathogenicity test, results of ANOVA showed no significant difference between the two experiments.
Differences in pathogenicity among the sensitivity groups were significant at $P<$ 0.0001 , but those between the fungicide dosage were not significant at $P=0.87$. However, the interaction between sensitivity group and fungicide dosage was significant at $P<0.0001$. There was no significant difference in average PBB among the three sensitivity groups in the nonfungicide control (Fig. 4). The three sensitivity groups were equally pathogenic to blos-

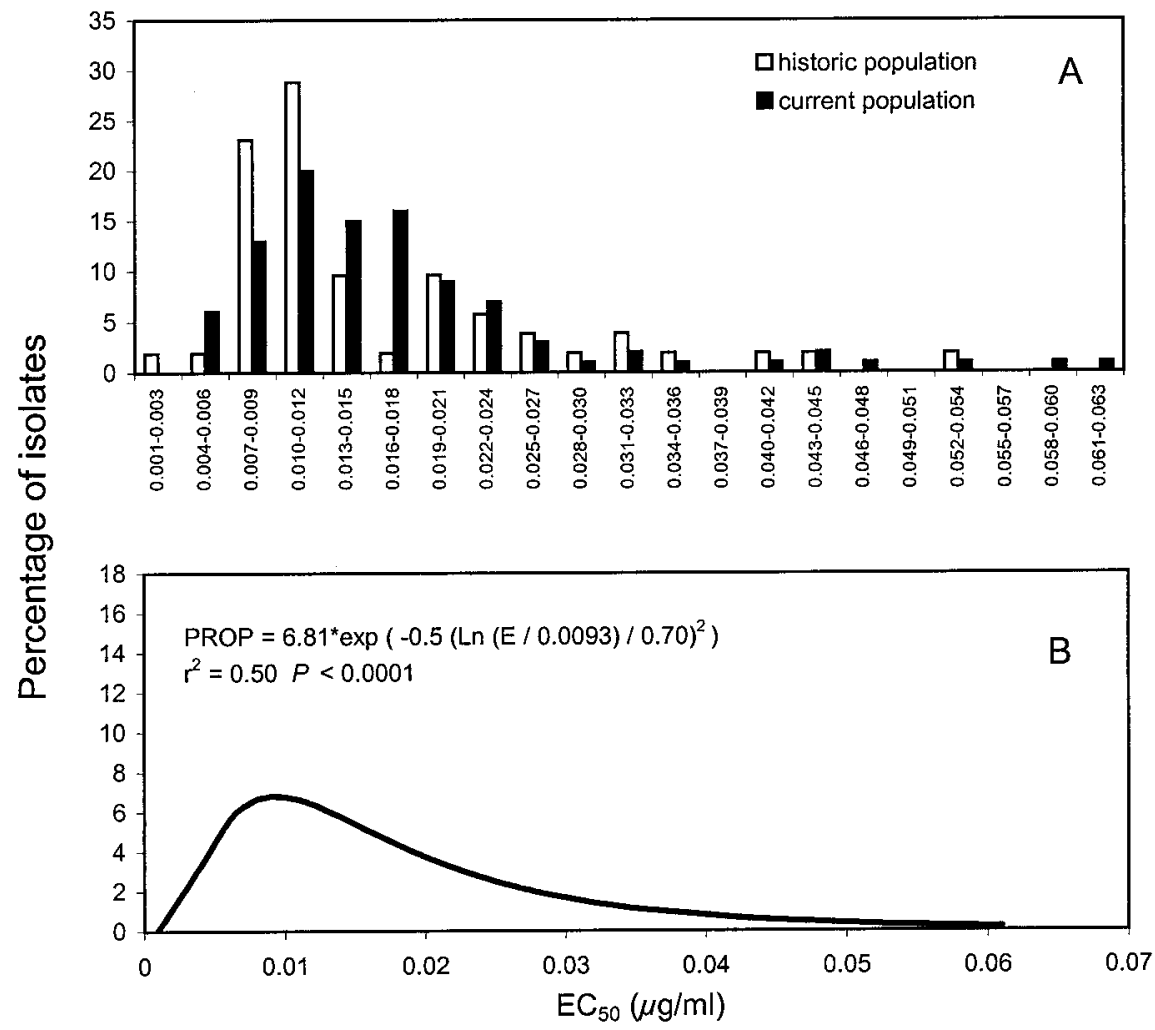

Fig. 3. Distribution of values for $50 \%$ effective concentration $\left(E_{50}\right)$ of tebuconazole in historic and current populations of Monilinia fructicola from stone fruit in California, A, The historic population was collected during 1992 to 1998 and the current population in 2002. The Kuiper test (NPAR1WAY procedure of SAS) showed no significant difference in distribution of $\mathrm{EC}_{50}$ values between these two populations. The data of the two populations were combined and, B, a lognormal regression described the distribution of $\mathrm{EC}_{50}$ values for the combined data.

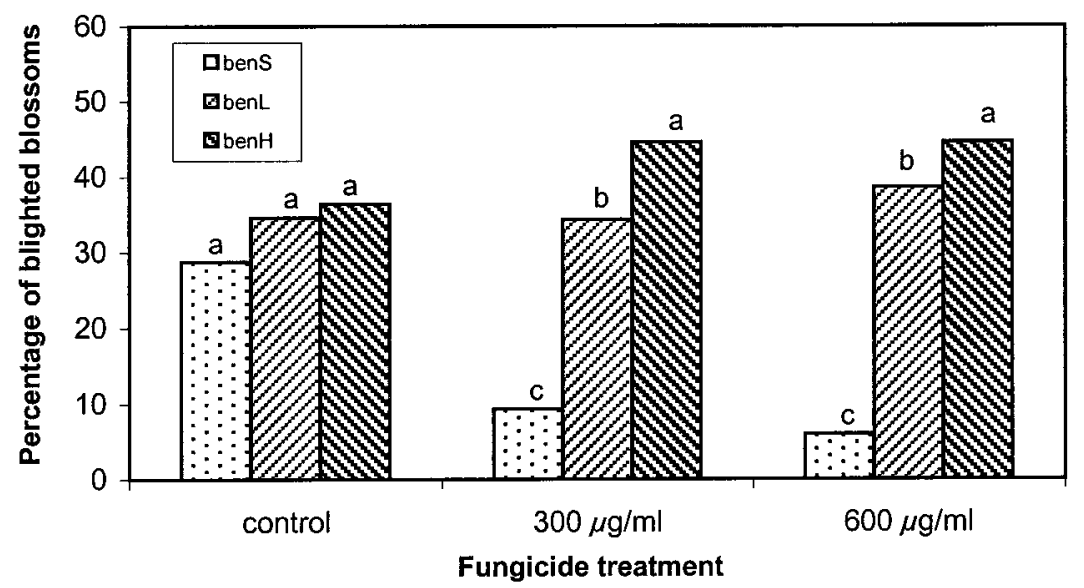

Fig. 4. Percentages of blighted nectarine blossoms inoculated with benzimidazole-sensitive (benS), low-resistant (benL), or high-resistant (benH) isolates of Monilinia fructicola. Prior to inoculation, blossoms were treated with thiophanate-methyl at 0,300 , or $600 \mu \mathrm{g} / \mathrm{ml}$. Different letters above bars indicate significant differences at $P=0.05$ using a least significant difference test. soms of nectarine. Both the full and half rates of thiophanate-methyl effectively controlled the disease caused by the benS isolates, but not the disease caused by the benL or benH isolates (Fig. 4). Regardless of the fungicide dosage, disease incidence was greatest on shoots inoculated with the benH isolates.

Competition among benzimidazole sensitivity groups. Analysis of the percentage of isolates recovered from blighted blossoms showed that both the effects of the sensitivity group and the interaction between sensitivity group and fungicide treatment were significant $(P<0.0001)$. The benS group did not have a competitive advantage in infecting the untreated blossoms. The 121 single-spore isolates recovered from blighted blossoms in the untreated control were distributed equally among the benS, benL, and benH groups, and no significant difference in the percentages of isolates among the groups was found (Fig. 5).

The application of thiophanate-methyl affected the frequencies of the different sensitivity groups recovered from the infected nectarine blossoms. Of the 128 single-spore isolates recovered from the half-dosage treatment, $3.8 \%$ were benS, $39.6 \%$ were benL, and $56.5 \%$ were benH isolates (Fig. 5). Of the 121 single-spore isolates recovered in the full dosage treatment, $1.5 \%$ were benS, $19.8 \%$ were benL, and $78.7 \%$ were benH isolates. The percentages among the sensitivity groups of isolates for the half- and full-dosage treatments were significantly different $(P<$ 0.05).

\section{DISCUSSION}

The survey results showed that two levels of resistance to benzimidazole fungicides, benL and benH, in isolates of $M$. fructicola have been present in California stone fruit orchards since at least 1998. Isolates were in three groups: (i) isolates with $\mathrm{EC}_{50}$ values less than $2.0 \mu \mathrm{g} / \mathrm{ml}$ were classified as benS, (ii) those with $\mathrm{EC}_{50}$ values greater than 2.0 but less than 30 $\mu \mathrm{g} / \mathrm{ml}$ as benL, and (iii) those with $\mathrm{EC}_{50}$ values greater than $30 \mu \mathrm{g} / \mathrm{ml}$ as benH. Previous reports of benomyl resistance in M. fructicola isolates from California showed only low levels of resistance with the $\mathrm{EC}_{50}$ value of $0.73 \mu \mathrm{g} / \mathrm{ml} \mathrm{(14)} \mathrm{or}$ growth at concentrations between 0.5 and $4 \mu \mathrm{g} / \mathrm{ml}(12,19)$, although highly resistant isolates have been reported in Michigan (9), South Carolina (27), New York (21), and Australia (23). This is the first report of high resistance to benzimidazole among M. fructicola isolates in California stone fruit orchards.

Lack of resistance to iprodione in isolates of M. fructicola is of major interest because this fungicide has been used extensively for over a decade in California stone fruit orchards. None of our isolates had $\mathrm{EC}_{50}$ values at the levels associated 
with resistance to iprodione. In this study, the highest $\mathrm{EC}_{50}$ value recorded was iprodione at $0.65 \mu \mathrm{g} / \mathrm{ml}$. In comparison, Elmer and Gaunt in New Zealand (6) reported $\mathrm{EC}_{50}$ values for resistant isolates of $\mu \mathrm{g}$ a.i. iprodione per $\mathrm{ml}$, and Ritchie (16) used a concentration of $25 \mu \mathrm{g} / \mathrm{ml}$ when studying $M$. fructicola isolates resistant to iprodione and other related fungicides. Based on these results, development of resistance to iprodione in the population of M. fructicola in California stone fruit orchards is unlikely to occur within the next few years. Iprodione resistance likely can be delayed even longer if the new fungicides with different modes of action are integrated into brown rot management programs.

The DMI fungicide tebuconazole was first applied in stone fruit orchards in 1997 in California. We observed no significant increase in $\mathrm{EC}_{50}$ values between the historic and current populations. However, Zehr et al. (27) reported that the $\mathrm{EC}_{50}$ values of M. fructicola isolates from South Carolina had increased after 3 years of exposure to propiconazole, but the isolates with lower sensitivities still were controlled by the fungicide. Wilcox and Burr (25) reported a baseline distribution of $\mathrm{EC}_{50}$ values to tebuconazole of $M$. fructicola ranging from 0.003 to $0.034 \mu \mathrm{g} / \mathrm{ml}$ with a mean of $0.007 \mu \mathrm{g} / \mathrm{ml}$, whereas Zehr et al. (27) reported a baseline $\mathrm{EC}_{50}$ range of 0.02 to $0.15 \mu \mathrm{g} / \mathrm{ml}$ with a mean of 0.03 $\mu \mathrm{g} / \mathrm{ml}$ for propiconazole. Our $\mathrm{EC}_{50}$ values, ranging from 0.001 to $0.0607 \mu \mathrm{g} / \mathrm{ml}$, fall within the reported baseline values.

The thiophanate-methyl-resistant isolates of $M$. fructicola were equal to the sensitive isolates in pathogenicity and competitiveness. When no fungicide was used, no significant differences in $\mathrm{PBB}$ among the benS, benL, and benH groups were found (Fig. 4). Similarly, the benL and benH isolate groups were equally competitive to the benS isolates when M. fructicola to be at between 3 and 217

nontreated nectarine blossoms were inoculated with a mixture containing equal proportions of the three groups of isolates (Fig. 5). The absence of differences in pathogenicity between sensitive and resistant M. fructicola isolates has been reported previously $(9,17,19)$, and the results of this study agree with those reports. However, differences in pathogenicity between sensitive and resistant isolates of $M$. fructicola $(9,18,20)$ and $M$. laxa $(4,5,13)$ also have been reported. These studies indicate that the fitness of benzimidazole-resistant isolates of $M$. fructicola may vary depending on the crop or location.

Thiophanate-methyl effectively controlled the disease caused by the sensitive isolates but not the resistant isolates. Our data showed that, when either the half or full dosages of thiophanate-methyl were used, the PBB caused by the benS group was effectively reduced (Fig. 4). Moreover, the benH group caused significantly higher PBB than the benL group did. When shoots were inoculated with equal amounts of conidia from each of the three sensitivity groups, the frequencies of the isolates recovered from the blighted blossoms shifted from equivalent percentages of the groups in the nonfungicide treatment to predominantly benL and benH groups in the fungicide treatments (Fig. 5). Both benL and benH groups had similar frequencies in the blossom treated with halfdose fungicide. However, the use of the full dosage of thiophanate-methyl appears to reduce the frequency of the benL group and favor the benH group. This supports previous reports of benomyl partially reducing the frequency of low-resistant isolates under orchard conditions $(1,14,19)$.

The competition experiment showed that a single application of thiophanatemethyl resulted in a shift in frequencies of resistant isolates from $67 \%$ in the inoculum used to inoculate the blossom to $98 \%$ from the blighted blossoms (Fig. 5). These

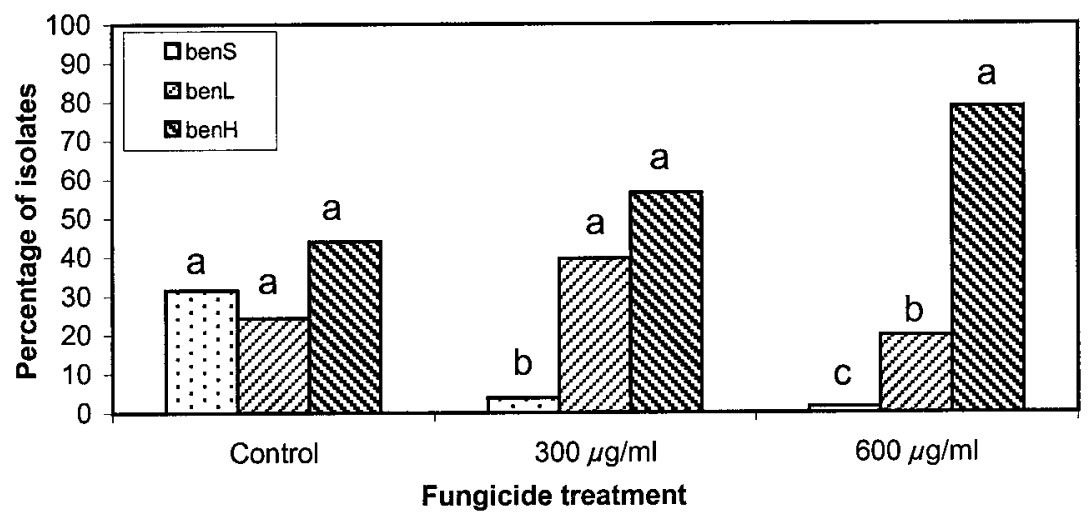

Fig. 5. Recovery of isolates of Monilinia fructicola from inoculations of nectarine blossoms with an equal mixture of conidia from benzimidazole-sensitive (benS), low-resistant (benL), and high-resistant (benH) isolates. Four isolates from each group were used, and the 12 isolates were mixed in similar spore proportions to co-inoculate nectarine blossoms. Before inoculation, shoots with blossoms were treated with thiophanate-methyl at 300 or $600 \mu \mathrm{g} / \mathrm{ml}$. Controls were not treated. Different letters above bars indicate significant differences among benS, benL, and benH isolates using a $\chi^{2}$ test. results are in agreement with previous field studies, in which the frequencies of benzimidazole-resistant isolates increased after a single application of benomyl from $20 \%$ in the inoculum source to $86 \%$ in blighted blossoms (21) and from 36 to $99 \%$ (19). Thus, surveys to determine the frequency of resistant isolates in pathogen populations would be important for disease management programs, especially prior to the use of any benzimidazole fungicide.

Resistance to both benzimidazole and dicarboximide fungicides has been reported for isolates of Botrytis cinerea in several crops (26). However, in this study, the thiophanate-methyl-resistant isolates did not show decreased sensitivity to iprodione. The results of this study also indicate that the use of iprodione would remain effective against benzimidazoleresistant isolates. Additionally, tebuconazole currently is registered and is an effective fungicide for the control of brown rot of stone fruit. Therefore, alternated applications of iprodione and tebuconazole would be an appropriate resistance management program.

The use of models to predict development of fungicide resistance in pathogen populations will greatly increase the effectiveness of integrated disease management strategies. This kind of model could optimize fungicide application strategy to minimize or slow the risk of fungicide resistance among fungal populations. Thus far, such models have not yet been developed for M. fructicola. This study provides estimates of parameters applicable for this modeling, such as the rate of change in frequency of resistant isolates over years, the possible competition process among isolates with different levels of fungicide resistance when individual inoculation or co-inoculation occur, and the changes in frequency of these isolates when fungicides are applied or not applied. These parameters also can be useful for models designed to determine the best fungicide application strategies for the control of brown rot of stone fruit.

\section{ACKNOWLEDGMENTS}

We thank B. L. Teviotdale, University of California Cooperative Extension, Kearney Agricultural Center, for critical comments.

\section{LITERATURE CITED}

1. Adaskaveg, J. E., Manji, B. T., and Ogawa, J. M. 1987. Stability and control of benomyl-resistant populations of Monilinia species in the absence or presence of benzimidazoles. (Abstr.) Phytopathology 77:1749.

2. Brent, J. K., and Hollomon, W. D. 1998. Fungicide Resistance: The Assessment of Risk. Global Crop Protection Federation (GCPF) Brussels, Belgium.

3. Byrde, R. J. W., and Willetts, H. J. 1977. The Brown Rot Fungi of Fruit: Their Biology and Control. Pergamon Press, Oxford and New York.

4. Cañez, V. M., Jr., and Ogawa, J. M. 1982. Reduced fitness of benomyl-resistant Monilinia laxa. (Abstr.) Phytopathology 72:980.

5. Cañez, V. M., Jr., and Ogawa, J. M. 1985. Parasitic fitness of benomyl-resistant and benomyl- 
sensitive Monilinia laxa. (Abstr.) Phytopathology 75:1329.

6. Elmer, P. A. G., and Gaunt, R. E. 1994. The biological characteristics of dicarboximideresistant isolates of Monilinia fructicola from New Zealand stone-fruit orchards. Plant Pathol. 43-130-137.

7. Gomez, K. A., and Gomez, A. A. 1984. Statistical Procedures for Agricultural Research. 2nd ed. John Wiley \& Sons, New York.

8. Hong, C. X., Holtz, B. A., Morgan, D. P., and Michailides, T. J. 1997. Significance of thinned fruit as a source of the secondary inoculum of Monilinia fructicola in California nectarine orchards. Plant Dis. 81:519-524.

9. Jones, A. L., and Ehret, G. R. 1976. Isolation and characterization of benomyl-tolerant strains of Monilinia fructicola. Plant Dis. Rep. 60:765-769.

10. Luo, Y., and Michailides, T. J. 2001. Factors affecting latent infection of prune fruit by Monilinia fructicola. Phytopathology 91:864872.

11. Luo, Y., Morgan, D. P., and Michailides, T. J. 2001. Risk analysis of brown rot blossom blight of prune caused by Monilinia fructicola. Phytopathology 91:759-768.

12. Michailides, T. J., Ogawa, J. M., and Opgenorth, D. C. 1987. Shift of Monilinia spp. and distribution of isolates sensitive and resistant to benomyl in California prune and apricot orchards. Plant Dis. 71:893-896.

13. Ogawa, J. M., Manji, B. T., Bostock, R. M., Canez, Jr. V. M., and Bose, E. A. 1984. Detection and characterization of benomyl-resistant
Monilinia laxa on apricots. Plant Dis. 68:29-31.

14. Osorio, J. M., Adaskaveg, J. E., and Ogawa, J. M. 1994. Inhibition of mycelial growth of Monilinia species and suppression and control of brown rot blossom blight of almond with iprodione and E-0858. Plant Dis. 78:712-716

15. Ritchie, D. F. 1982. Effect of dichloran, iprodione, procymidone, and vinclozolin on the mycelial growth, sporulation, and isolation of resistant strains of Monilinia fructicola. Plant Dis. 66:484-486.

16. Ritchie, D. F. 1983. Mycelial growth, peach fruit-rotting capability, and sporulation of strains of Monilinia fructicola resistant to dichloran, iprodione, procymidone, and vinclozolin. Phytopathology 73:44-47.

17. Sanoamuang, N., and Gaunt, R. E. 1995. Persistence and fitness of carbendazim-resistant and dicarboximide-resistant isolates of Monilinia fructicola (Wint.) Honey in flowers, shoots and fruit of stone fruit. Plant Pathol. 44:448-457.

18. Sonoda, R. M., and Ogawa, J. M. 1982. Growth rate of Monilinia fructicola resistant and sensitive to benomyl on potato-dextrose agar and on peach fruit. Plant Dis. 66:11551156.

19. Sonoda, R. M., Ogawa, J. M., Manji, B. T., Shabi, E., and Rough, D. 1983. Factors affecting control of blossom blight in a peach orchard with low level benomyl-resistant Monilinia fructicola. Plant Dis. 67:681-684.

20. Sonoda, R. M., Ogawa, J. M., and Sholberg, P. L. 1982. Competition between conidial isolates of benomyl resistant and benomyl sensitive
Monilinia fructicola on peach fruit. (Abstr.) Phytopathology 72:988

21. Szkolnik, M., and Gilpatrick, J. D. 1977 Tolerance of Monilinia fructicola to benomyl in western New York State orchards. Plant Dis. Rep. 61:654-657.

22. Szkolnik, M., Ogawa, J. M., Manji, B. T., Frate, C. A., and Bose, E. A. 1978. Impact of benomyl treatments on populations of benomyl-tolerant Monilinia fructicola. (Abstr.) Phytopathol. News 12:239.

23. Whan, J. H. 1976. Tolerance of Sclerotinia fructicola to benomyl. Plant Dis. Rep. 60:200201.

24. Wherrett, A. D., Sivasithamparam, K., and Kumar, S. 2001. Detection of possible sys temic fungicide resistance in Western Australian Monilinia populations. (Abstr.) Phytopathology 91:S95.

25. Wilcox, W. F., and Burr, J. A. 1994. Base-line sensitivity of Monilinia fructicola to six DMI fungicides. (Abstr.) Phytopathology 84:1078

26. Yourman, L. F., and Jeffers, S. N. 1999. Resistance to benzimidazole and dicarboximide fungicides in greenhouse isolates of Botrytis cinerea. Plant Dis. 83:569-575.

27. Zehr, E. I., Luszcz, L. A., Olein, W. C., Newall, W. C., and Toler, J. E. 1999. Reduced sensitivity in Monilinia fructicola to propiconazole following prolonged exposure in peach orchards. Plant Dis. 83:913-916.

28. Zehr, E. I., Toler, J. E., and Luszcz, L. A. 1991. Spread and persistence of benomyl-resistan Monilinia fructicola in South Carolina peach orchards. Plant Dis. 75:590-593. 